\title{
Socioeconomic Position, Maternal IQ, Home Environment, and Cognitive Development
}

\author{
Shilu Tong, PhD, Peter Baghurst, PhD, Graham Vimpani, PhD, and Anthony McMichael, PhD
}

Objective To assess whether socioeconomic position, maternal intelligence (IQ), and the home environment are interrelated to cognitive development in childhood.

Study design Prospective cohort study $(n=723)$ with cognitive tests at ages 2, 4, 7, and 11 to 13 years.

Results There were statistically significant positive associations of father's occupational prestige, Home Observation for Measurement of Environment (HOME) score, and maternal IQ with cognitive performance in childhood. After adjustment for confounding factors, there was an increase in cognitive development by 0.8 to 2.0, 2.9 to 4.8 , and 4.2 to 9.0 points for a 10 -unit increment in father's occupational prestige, maternal IQ, and HOME score, respectively.

Conclusions These results demonstrate that socioeconomic position, maternal IQ, and the home environment are independently and positively predictive of children's cognitive development. These findings provide additional rationale for implementing social policies that reduce socioeconomic inequalities. (J Pediatr 2007;151:284-8)

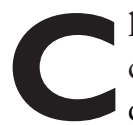

hildhood intelligence (IQ) is a predictor of various health outcomes in adulthood (eg, cardiovascular disease, some cancers, diabetes, suicide, motor vehicle injuries, and premature deaths). ${ }^{1-6}$ Hence, a better understanding of the determinants of child IQ should assist in the reduction of lifetime risks to health.

Several explanations for the association between IQ and adult health have been advanced, ${ }^{7}$ including that IQ is 1$)$ a predictor of health-favoring social circumstances in later life (eg, high educational attainment and high job status); 2) a cumulative index of psychological and physiological insults (eg, birth complications, suboptimal postnatal care, and illness); 3) an intrinsic indicator of general body integrity (as measured via the brain's capacity to process information rapidly, correctly, and reliably); 4) a proxy for stress management skills - people with higher intelligence scores may be less likely to place themselves in stressful environments or cope better if they do; or 5) an asset for optimal interpretation of health prevention messages - children who scored highly in intelligence tests were more likely to give up smoking in adult life. ${ }^{8}$

The relative roles of socioenvironmental and genetic factors in cognitive development remain unresolved. Although a proportion of the variation in human intelligence may be attributable to genetic factors, ${ }^{9}$ socioenvironmental factors are important determinants of childhood IQ and are modifiable through a range of early-years intervention strategies such as early childhood education and care. ${ }^{10,11} \mathrm{~A}$ number of studies have examined the link between socioeconomic characteristics and cognitive development. ${ }^{12-14}$ In general, children in disadvantaged families manifest poorer cognitive performance than do those in better-off families. However, few studies have adjusted satisfactorily for parental and environmental factors that may confound the relation between socioeconomic backgrounds and cognitive development. For example, children in disadvantaged families may be more exposed to environmental neurotoxins such as lead and other chemicals and may have poorer quality of home environment. ${ }^{15-21}$

In this study, we examined the association of socioeconomic position, maternal IQ, and the home environment with cognitive development during childhood, using data from a prospective cohort study design that enabled adjustment for a wide range of confounding factors.

\begin{tabular}{clll}
\hline HOME & $\begin{array}{c}\text { Home Observation for Measurement of } \\
\text { Environment }\end{array}$ & IQ & Intelligence Quotient \\
& MDI & Mental Development Index
\end{tabular}

From the School of Public Health Queensland University of Technology, Kelvin Grove, Australia (S.T.); the Public Health Research Unit, Children, Youth, and Women's Health Service, and Disciplines of Paediatrics and Public Health, University of Adelaide, Adelaide, Australia (P.B.); The Discipline of Paediatrics and Child Health, University of Newcastle, Newcastle, Australia (G.V.); and the National Centre for Epidemiology and Population Health, Australian National University, Canberra, Australia (A.M.)

Supported by a series of grants from the National Health and Medical Research Council and the Channel 7 Children's Research Foundation; Dr Shilu Tong is supported by an NHMRC Research Fellowship.

Submitted for publication Sep 16, 2006; last revision received Jan 16, 2007; accepted Mar 15, 2007

Reprint requests: Dr Shilu Tong, School of Public Health, Queensland University of Technology, Kelvin Grove, Qld. 4059, Australia. E-mail: s.tong@qut.edu.au. 0022-3476/\$ - see front matter

Copyright (C) 2007 Mosby Inc. All rights reserved.

| 0.1 0 | 6/j.jpeds.2007.03.020 


\section{METHODS}

The primary objective of the Port Pirie Cohort Study was to examine the relation between exposure to environmental lead and child development. The children living in and around the lead-smelting town of Port Pirie, South Australia, were followed from birth to age 11 to 13 years. Details of the research design have been reported elsewhere. ${ }^{17-21}$

\section{Sample}

Of the 723 live births who were originally recruited in the Port Pirie Cohort Study, 601, 548, 494, and 375 were followed and assessed, respectively, at ages 2, 4, 7, and 11 to 13 years. The children who were evaluated at each age differed little from those lost to follow-up on most characteristics, including sociodemographic, environmental, and biomedical factors, except that they lived in families with slightly higher social class than those lost to followup. ${ }^{17-21}$ For example, possible loss to follow-up bias was evaluated at age 11 to 13 years. The results show that 55 children lost to follow-up were in families that either left the Port Pirie district or could not be contacted despite intensive efforts (ie, $11.7 \%$ of the base population), although a small number of families (7.8\%) simply discontinued their participation. ${ }^{19}$

\section{Measurements of Socioeconomic Characteristics}

A crude measure of children's socioeconomic position often used in Australia is the Daniel Scale, ${ }^{22}$ which is based on the hierarchy of the father's occupational prestige and is used as an approximate indicator of family income. The Daniel score is inversely related to occupational prestige, that is, the higher the Daniel score, the lower the prestige. For example, a manufacturing worker was scored much higher than a professional occupation (eg, manager or engineer). The Daniel score of each family at birth was used in this study, as some evidence suggests that the father's social class at birth is an important predictor of child's IQ. ${ }^{13,23}$ Two important predictors of children's abilities are the Home Observation for Measurement of the Environment (HOME) inventory ${ }^{24}$ and maternal IQ. The HOME inventory was used to assess each child's caregiving environment, when each child was 3 years of age. Maternal IQ was measured with the Wechsler Adult Intelligence Scale-Revised, ${ }^{25}$ whereas the children were in the age range of 3 to 5 years. Maternal IQ rather than maternal education was used in this study because the former combines both inherited and acquired cognitive capacity and is a better integrated predictor of children's IQ than is the latter.

\section{Measurement of Cognitive Function}

Each child's abilities were assessed by using the Bayley Scales of Infant Development at age 2 years, ${ }^{26}$ the McCarthy Scales of Children's Abilities at age 4 years, ${ }^{27}$ and the revised version of the Wechsler Intelligence Scale for Children
(WISC-R) at ages 7 and 11 to 13 years. ${ }^{28}$ The Bayley Scales of Infant Development, which comprises two standardized scores, the Mental Development Index (MDI) and Psychomotor Development Index, is suitable for children ages 30 months and younger. Only MDI scores were used in this study because MDI score primarily reflects cognitive abilities. The McCarthy Scales of Children's Abilities, which are applicable to children 3 to 7 years old, comprises five scales: verbal, perceptual performance, quantitative, memory, and motor. The first three of those scales combined form the general cognitive index. The WISC-R was used to assess the cognitive function of each child at ages 7 and 11 to 13 years. The WISC-R is a test of general intelligence developed for use with children ages 6 to 16 years. All children were assessed at each age by a research psychologist who was unaware of children's socioeconomic characteristics.

\section{Confounders}

Information was also collected on the following potential confounding variables: child's sex, birth weight, head circumference, birth length, Apgar score at 5 minutes after birth, presence of neonatal jaundice, maternal age, duration of gestation, maternal smoking and drinking habits, parental marital status, and lifetime average blood lead concentration up to age 2 years. Birth weight was measured in the clinical setting and recorded in grams. Duration of gestation was calculated from the date of the last menstrual period reported by the mother and checked against medical records. The child's head circumference and birth length were also measured immediately after delivery. To assess early-life exposure to environmental lead, sequential blood samples were collected from the pregnant women, the umbilical cord, at 6,12 , and 24 months, and then periodically from the young child. The lifetime average blood lead concentration up to 2 years was used in this study because we had previously found that lead exposure in the first 2 years of life is most critical to cognitive development. ${ }^{17-21}$

\section{Analysis}

We first examined univariate relations between socioeconomic characteristics and cognitive development. All available data were retrieved for the 601 children whose cognitive function was initially assessed at age 2 years. Analysis of variance was used to test for linear trend across groups defined on the basis of the quintiles, separately for each of three indices: the Daniel Scale, the HOME score, and maternal IQ. Covariates that might confound the association between socioeconomic characteristics and cognitive function were explored. Multiple linear regression model was then used to examine the association of occupational prestige, maternal IQ and home environment, with cognitive development as measured at ages 2, 4, 7, and 11 to 13 years, after adjustment for a range of potential confounding factors. 


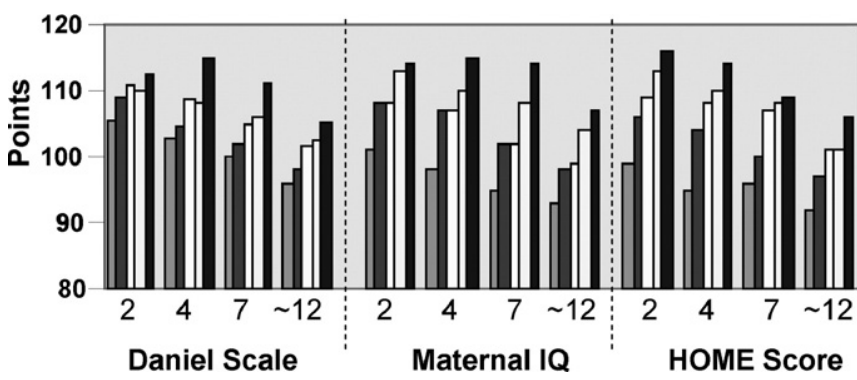

Figure I. Socioeconomic characteristics and children's IQ at ages 2, 4, 7, and 11 to 13 years (quintile 1 represents the lowest father's occupational prestige, HOME scores, and maternal IQ; quintile 5 represents the highest father's occupational prestige, HOME scores, and maternal IQ). ㅁ Quintile 1; ㅁ Quintile 2; ㅁ Quintile 3; ㅁ Quintile 4; $\boldsymbol{\square}$ Quintile 5.

\section{RESULTS}

\section{Overview of the Predictors of Cognitive Development}

The mean value of cognitive scores at ages $2,4,7$, and 11 to 13 years was $109.2,107.1,104.7$, and 100.0, respectively. The father's occupational prestige, HOME score, and maternal IQ were clearly associated with cognitive function at all ages examined $(P \leq .01)$, and there appeared to be a consistent dose-response relation (Figure 1).

\section{Daniel Scale and Cognitive Development}

Table I (available at www.jpeds.com) presents a statistically significant positive association between father's occupational prestige and children's cognitive function at ages 2, 4, 7 , and 11 to 13 years in simple (unadjusted) regression analyses. Children whose father's occupational prestige was low had poorer cognitive function than those whose father's occupational prestige was higher. The strength of the association decreased slightly after adjustment for a range of putative confounders (model I).

The association between father's occupational prestige and children's cognitive function was attenuated by adjustment for maternal IQ (model II) and quality of home environment (model III). However, the relation remained statistically significant or marginally significant.

\section{Maternal IQ, Quality of Home Environment, and Cognitive Development}

Similar patterns were observed for maternal IQ (Table II; available at www.jpeds.com) and quality of home environment (Table III; available at www.jpeds.com). Statistically significant and positive associations were observed for those two indices across different ages in simple (unadjusted) regression analyses. Children whose mother's IQ or quality of home environment (HOME score) was low had poorer cognitive function than those whose mother's IQ or HOME score was higher. The magnitude of the association decreased slightly after adjustment for a set of confounders (models I through III). However, after that adjustment there remained a statistically significant association of mother's IQ and
HOME score with children's cognitive development across childhood.

\section{Socioeconomic Position, Maternal IQ, Quality of Home Environment, and Cognitive Development: A Comparison}

Further analyses display a consistent relation between these predictors and cognitive development after adjustment for confounding factors in the final model. For example, for every 10-unit increase in father's occupational prestige, children's cognitive performance increased by 0.8 ( $95 \% \mathrm{CI}:-0.7$ to 2.3 ), 1.5 (95\% CI: 0.1 to 2.9 ), 2.0 (95\% CI: 0.5 to 3.4 ), and 1.1 (95\% CI: -0.4 to 2.6 ) points at ages $2,4,7$, and 11 to 13 years, respectively. There was a similar pattern for the effect of maternal IQ on cognitive performance by age. For every 10-unit increase in HOME scores, children's cognitive performance improved by 9.0 (95\% CI: 5.4 to 12.7 ), 7.7 (95\% CI: 4.2 to 11.3$), 4.2$ (0.7 to 7.6 ), and 6.2 (95\% CI: 2.5 to 9.9 ) points at ages $2,4,7$, and 11 to 13 years, respectively (Figure 2).

\section{DISCUSSION}

In this cohort of children, socioeconomic position, maternal IQ and the quality of home environment were consistently associated with cognitive development, even after adjustment for a wide range of confounders. Our results indicate that the three measures of socioeconomic characteristics have an independent impact on childhood cognitive development. In general, the higher the occupational prestige and maternal IQ and the better the home environment, the higher the children's cognitive function.

We also found that the association between socioeconomic position and cognitive development was markedly attenuated by adjustment for maternal IQ and quality of home environment. It suggests that it is important to take these factors into account in the assessment of the association between socioeconomic position and childhood intelligence. The results of this study also indicate that other parental factors (eg, parental smoking behavior) and environmental variables (eg, lead exposure) are unlikely to explain the association between socioeconomic characteristics and cognitive development. Further, there were different patterns for the effects of HOME score versus maternal IQ or father's occupational prestige on cognitive performance (Figure 2). This suggests that the quality of home environment may influence cognitive development through different mechanisms and/or pathways to maternal IQ or father's occupational prestige. In particular, it appears that the quality of home environment has maximal impact in early childhood, and the other two variables have maximal impact in later childhood.

Several studies have examined the association between socioeconomic status and cognitive function. Kaplan et $\mathrm{a}^{12}$ undertook a population-based study of 496 Finnish men ages 58 and 64 for whom there were data on parent's socioeconomic position, their own education level, and performance on neuropsychological tests. They reported childhood socio- 


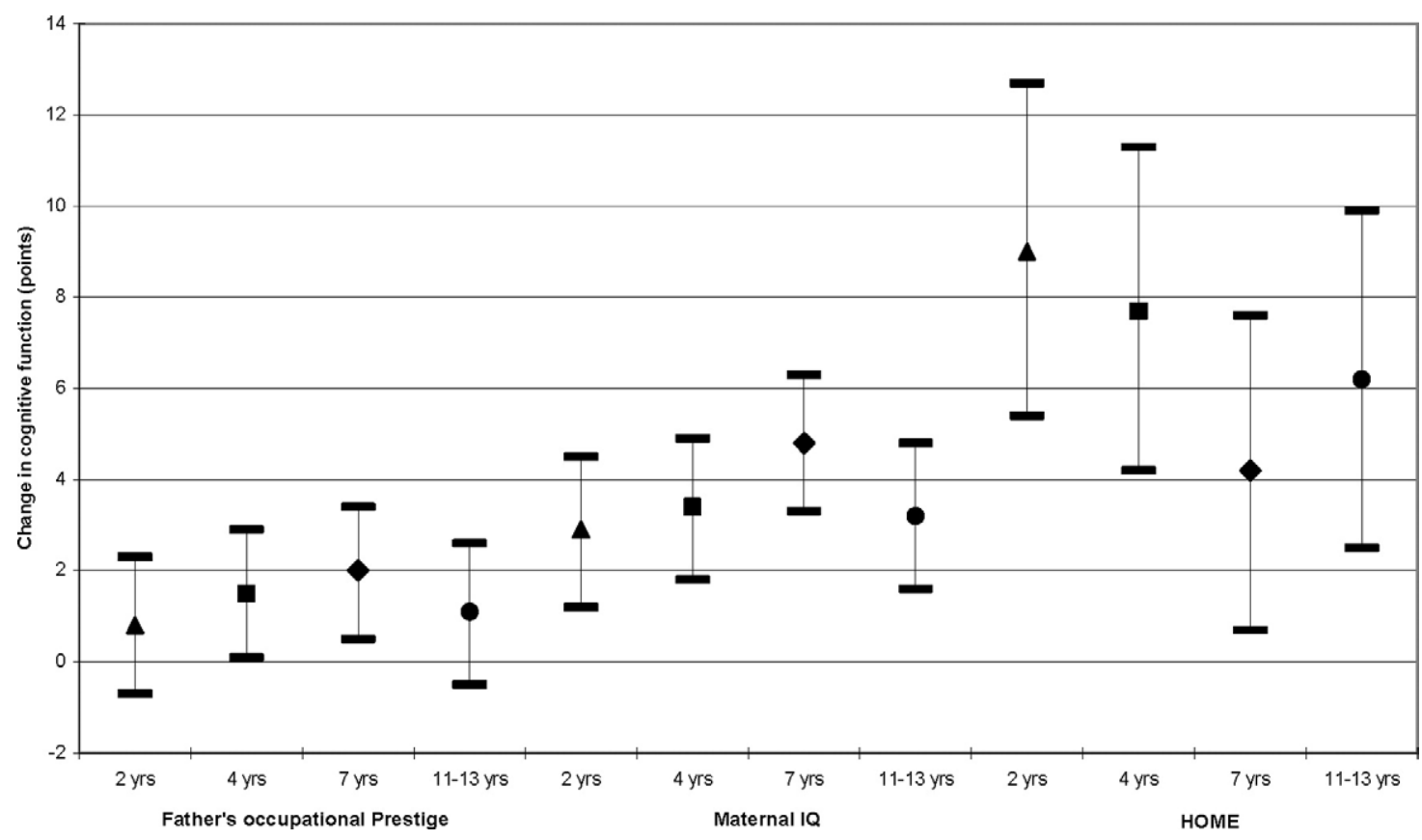

Figure 2. Adjusted relations of socioeconomic factors to cognitive development by age.

economic position to be positively associated with cognitive function in adulthood. Jefferis et $\mathrm{al}^{13}$ examined the combined effect of social class and birth weight on cognitive development and found that the postnatal socioeconomic environment has a substantial impact on cognitive function through to early adulthood. More recently, Lawlor et $\mathrm{al}^{23}$ reported that father's social class at the time of birth was an important predictor of childhood intelligence, even after adjustment for maternal characteristics and perinatal and childhood factors. Our findings are essentially consistent with the findings of these studies. Although both maternal IQ and quality of home environment are important determinants of children's cognitive function, ${ }^{29-31}$ there are few empirical data on how these factors inter-relate to each other. The results of this study demonstrate that maternal IQ and quality of home environment tend to have independent impacts on children's cognitive development.

There are three major strengths in this study. We systematically examined the inter-relations between socioeconomic characteristics and cognitive development after adjustment for a wide range of confounding factors (including parental smoking and lead exposure). Second, a relatively homogenous community-based sample was used. For example, all children involved in the study were Caucasian, and therefore the assessment is unlikely to be confounded by cultural factors. Finally, internationally standardized tests of cognitive function were used at various ages, and stringent quality control procedures were implemented in this study. ${ }^{17-21}$

This study has three possible limitations. First, follow-up bias could have arisen if the children who left the study differ-in the relation that they display between their socioeconomic characteristics and cognitive development-from those who remained in the study. However, any such bias is unlikely to be substantial because our analyses showed that the children who were evaluated at ages 11 to 13 years did not differ significantly from those lost to follow-up on most characteristics, including sociodemographic, environmental, and biomedical factors, except that fathers of the children remaining in the cohort had slightly higher occupational prestige than those lost to followup. ${ }^{17-21}$ Therefore, to maximize available information, we used the total dataset available at each age $(2,4,7$, and 11 to 13 years); the longitudinal analysis of only those subjects who contributed data at all four ages revealed a similar pattern. Second, there is no recognized gold standard for measuring socioeconomic characteristics. We used the Daniel scale, the HOME score, and maternal IQ to measure child's socioeconomic characteristics. Nevertheless, these indices may not fully reflect all potentially relevant childhood socioeconomic background, and residual confounding (eg, by paternal IQ) may exist. Finally, this study is unavoidably unable to distinguish between a genetic and an environmental effect of maternal IQ on cognitive development.

The findings of this study have two important pubic health implications. First, socioeconomic attributes appear to be independently and positively predictive of children's cognitive function. The association between socioeconomic characteristics and cognitive development is unlikely to be explained by other parental factors (eg, parental smoking behaviour) and environmental variables (eg, lead exposure). Second, socioeconomic characteristics may directly or indirectly contribute to the documented relation between childhood intelligence and adult morbidity and mortality as they are major determinants of cognitive development.

The authors particularly wish to thank the families who participated in this study. 


\section{REFERENCES}

1. Gunnell D, Magnusson PK, Rasmussen F. Low intelligence test scores in 18 year old men and risk of suicide: cohort study. BMJ 2005;330:167.

2. Batty GD, Mortensen EL, Nybo Andersen AM, Osler M. Childhood intelligence in relation to adult coronary heart disease and stroke risk: evidence from a Danish birth cohort study. Paediatr Perinat Epidemiol 2005;19:452-9.

3. Hart CL, Taylor MD, Smith GD, Whalley LJ, Starr JM, Hole DJ, et al. Childhood IQ and all-cause mortality before and after age 65: prospective observational study linking the Scottish Mental Survey 1932 and the Midspan studies. Br J Health Psychol 2005;10:153-65.

4. Hart CL, Taylor MD, Smith GD, Whalley LJ, Starr JM, Hole DJ, et al. Childhood IQ and cardiovascular disease in adulthood: prospective observational study linking the Scottish Mental Survey 1932 and the Midspan studies. Soc Sci Med 2004;59:2131-8.

5. Martin LT, Fitzmaurice GM, Kindlon DJ, Buka SL. Cognitive performance in childhood and early adult illness: a prospective cohort study. J Epidemiol Community Health 2004;58:674-9.

6. Hart CL, Taylor MD, Davey Smith G, Whalley LJ, Starr JM, Hole DJ, et al. Childhood IQ, social class, deprivation, and their relationships with mortality and morbidity risk in later life: prospective observational study linking the Scottish Mental Survey 1932 and the Midspan studies. Psychosom Med 2003;65:877-83.

7. Whalley LJ, Deary IJ. Longitudinal cohort study of childhood IQ and survival up to age 76. BMJ 2001;322:819-21.

8. Taylor MD, Hart CL, Davey Smith G, Starr JM, Hole DJ, Whalley LJ, et al. Childhood mental ability and smoking cessation in adulthood: prospective observational study linking the Scottish mental survey 1932 and the Midspan studies. J Epidemiol Community Health 2003;57:464-5.

9. Posthuma D, Luciano M, Geus EJ, Wright MJ, Slagboom PE, et al. A genomewide scan for intelligence identifies quantitative trait loci on $2 \mathrm{q}$ and $6 \mathrm{p}$. Am J Hum Genet 2005;77:318-26.

10. Hatcher PJ, Goetz K, Snowling MJ, Hulme C, Gibbs S, Smith G. Evidence fo the effectiveness of the Early Literacy Support programme. Br J Educ Psychol 2006;76:351-67.

11. Tong S, Baghurst P, McMichael A. Birthweight and cognitive development during childhood. J Paediatr Child Health 2006;42:98-103.

12. Kaplan GA, Turrell G, Lynch JW, Everson SA, Helkala EL, Salonen JT. Childhood socioeconomic position and cognitive function in adulthood. Int J Epidemiol 2001;30:256-63.

13. Jefferis BJ, Power C, Hertzman C. Birth weight, childhood socioeconomic environment, and cognitive development in the 1958 British birth cohort study. BMJ 2002;325:305-14
14. Lee S, Kawachi I, Berkman LF, Grodstein F. Education, other socioeconomic indicators, and cognitive function. Am J Epidemiol 2003;157:712-20.

15. Ascioglu M, Dolu N, Golgeli A, Suer C, Ozesmi C. Effects of cigarette smoking on cognitive processing. Int J Neurosci 2004;114:381-90.

16. Tong S, McMichael AJ. Maternal smoking and neuropsychological development in childhood: a review of evidence. Dev Med Child Neurol 1992;34:191-7.

17. McMichael AJ, Baghurst PA, Wigg NR, Vimpany GV, Robertson EF, Roberts RJ. Port Pirie Cohort Study: environmental exposure to lead and children's abilities at the age of four years. N Engl J Med 1988;319:468-75.

18. Baghurst PA, McMichael AJ, Wigg NR, Vimpany GV, Robertson EF, Roberts RJ, Tong SL. Environmental exposure to lead and children's intelligence at the age of seven years: the Port Pirie Cohort Study. N Engl J Med 1992;327:1279-84.

19. Tong SL, Baghurst PA, McMichael AJ, Sawyer M, Burns JM. Lifetime exposure to environmental lead and children's intelligence at ages 11-13 years. BMJ 1996;312:1569-75.

20. Tong SL, Baghurst P, Sawyer M, Burns JM, McMichael AJ. Declining blood lead levels and changes in cognitive function during childhood: the Port Pirie Cohort Study. JAMA 1998;280:1915-9.

21. Burns JM, Baghurst P, Sawyer M, McMichael AJ, Tong SL. Lifetime low-level exposure to environmental lead and children's emotional and behavioural development at ages 11-13 years: the Port Pirie Cohort Study. Am J Epidemiol 1999;149:740-9.

22. Daniel A. The measurement of social class. Comm Health Studies 1984;3:218-22.

23. Lawlor DA, Batty GD, Morton SMB, Deary IJ, Macintyre S, Ronalds G, et al. Early life predictors of childhood intelligence: evidence from the Aberdeen children of the 1950s study. J Epidemiol Community Health 2005;59:656-63.

24. Caldwell B, Bradley R. Home observation for measurement of the environment. New York: Dorsey, 1985.

25. Wechsler D. Wechsler adult intelligence scale - revised. New York: Psychological Corporation USA, 1985

26. Bayley N. Bayley Scales of Infant Development. New York: The Psychologic Corporation, 1969.

27. McCarthy D. Manual for the McCarthy Scales of Children's Abilities. New York: The Psychologic Corporation, 1972.

28. Wechsler D. Manual for the Wechsler Intelligence Scale for Children - Revised. New York: Psychological Corporation, 1974.

29. Bradley RH, Whiteside-Mansell L. Home Environment and Children's Development. In: Families, risk, and competence. Editors: Lewis M, Feiring C. Mahwah, NJ: Lawrence Erlbaum, 1998, pp 133-60.

30. Sternberg RJ, Grigorenko EL. Environmental effects on cognitive abilities. Mahwah, NJ: L. Erlbaum Associates, 2001.

31. Grigorenko E. Heritability and Intelligence. In: Handbook of intelligence. Editor: Sternberg RJ. Cambridge/New York: Cambridge University Press, 2000, pp 53-91. 
Table I. Regression coefficients $(95 \% \mathrm{Cl})$ of father's occupational prestige as a predictor of cognitive development

\begin{tabular}{ccccc}
\hline & & \multicolumn{3}{c}{ Adjusted* } \\
\cline { 3 - 5 } Age $(\mathbf{y})$ & Unadjusted & Model I & Model II & Model III \\
\hline 2 & 0.28 & $0.26(0.14,0.37)$ & $0.16(0.02,0.31)$ & $0.08(-0.07,0.23)$ \\
4 & 0.34 & $0.27(0.15,0.39)$ & $0.22(0.08,0.37)$ & $0.15(0.01,0.29)$ \\
7 & 0.33 & $0.31(0.19,0.43)$ & $0.24(0.09,0.38)$ & $0.20(0.05,0.34)$ \\
$I I-13$ & 0.30 & $0.23(0.11,0.36)$ & $0.15(-0.01,0.30)$ & $0.11(-0.04,0.26)$ \\
\hline
\end{tabular}

*Model I: Variables that were adjusted for included child's sex, birth weight, head circumference, birth length, Apgar score at 5 minutes, neonatal jaundice, maternal age, duration of gestation, maternal smoking and drinking habits, parental marital status, and lifetime average blood lead concentration up to age 2 years; model II: all the variables in model I plus maternal IQ; model III: all the variables in model II plus HOME.

Table II. Regression coefficients $(95 \% \mathrm{Cl})$ of maternal IQ as a predictor of cognitive development

\begin{tabular}{ccccc}
\hline & & \multicolumn{3}{c}{ Adjusted* } \\
\cline { 3 - 5 } Age $(\mathbf{y})$ & Unadjusted & Model I & Model II & Model III \\
\hline 2 & 0.44 & $0.43(0.27,0.58)$ & $0.40(0.25,0.56)$ & $0.29(0.13,0.45)$ \\
4 & 0.56 & $0.50(0.35,0.64)$ & $0.45(0.30,0.60)$ & $0.34(0.18,0.50)$ \\
7 & 0.57 & $0.57(0.43,0.71)$ & $0.53(0.39,0.47)$ & $0.48(0.33,0.63)$ \\
$I I-13$ & 0.46 & $0.41(0.26,0.56)$ & $0.41(0.25,0.56)$ & $0.32(0.16,0.48)$ \\
\hline
\end{tabular}

*Model I: Variables that were adjusted for included child's sex, birth weight, head circumference, birth length, Apgar score at 5 minutes, neonatal jaundice, maternal age, duration of gestation, maternal smoking and drinking habits, parental marital status, and lifetime average blood lead concentration up to age 2 years; model II: all the variables in model I plus Daniel scores; model III: all the variables in model II plus HOME.

Table III. Regression coefficients $(95 \% \mathrm{Cl})$ of quality of home environment as a predictor of cognitive development

\begin{tabular}{|c|c|c|c|c|}
\hline \multirow[b]{2}{*}{ Age (y) } & \multirow[b]{2}{*}{ Unadjusted } & \multicolumn{3}{|c|}{ Adjusted* } \\
\hline & & Model I & Model II & Model III \\
\hline 2 & 1.21 & $\mathrm{I} . \mathrm{I} 3(0.85, \mathrm{I} .4 \mathrm{I})$ & $\mathrm{I} .03(0.74, \mathrm{I} .33)$ & $0.90(0.54,1.27)$ \\
\hline 7 & 1.02 & $0.82(0.53, \mathrm{I} . \mathrm{II})$ & $0.65(0.35,0.95)$ & $0.42(0.07,0.76)$ \\
\hline $11-13$ & 1.06 & $0.95(0.66,1.24)$ & $0.86(0.55,1.16)$ & $0.62(0.25,0.99)$ \\
\hline
\end{tabular}

*Model I: Variables that were adjusted for included child's sex, birth weight, head circumference, birth length, Apgar score at 5 minutes, neonatal jaundice, maternal age, duration of gestation, maternal smoking and drinking habits, parental marital status, and lifetime average blood lead concentration up to age 2 years; model II: all the variables in model I plus Daniel scores; model III: all the variables in model II plus maternal IQ. 